\title{
An evaluation of paediatric medicines reconciliation at hospital discharge into the community
}

Chi Huynh ${ }^{1,2}$, Ian Chi Kei Wong ${ }^{1,3}$, Stephen Tomlin ${ }^{4}$, Ellisha Halford ${ }^{1,4}$, Yogini Jani ${ }^{1,5}$, Maisoon Ghaleb 6

Centre for Paediatric Pharmacy Research, Department of Practice and Policy, UCL School of Pharmacy, UK ${ }^{1}$

Academic Practice Unit, Pharmacy Department, Birmingham Children's Hospital, UK. ${ }^{2}$

Centre for Safe Medication Practice and Research. Department of Pharmacology \& Pharmacy, Li Ka Shing Faculty of Medicine, University of Hong Kong, China. ${ }^{3}$

Evelina London Children's Hospital. Guy's and St Thomas NHS Foundation Trust, King's Health Partners, London, UK. ${ }^{4}$

University College London Hospitals NHS Foundation Trust ${ }^{5}$

Department of Pharmacy, School of Life and Medical Sciences, University of Hertfordshire, $U K^{6}$

Corresponding author: Maisoon Ghaleb drmghaleb@gmail.com

Address: Department of Pharmacy, School of Life and Medical Sciences, University of Hertfordshire, Hatfield, AL10 9AB, United Kingdom.

\section{Contributorship statement}

Chi Huynh contributed towards the conception of the study design, was responsible for part of the acquisition of data across one site, analysis and interpretation of the complete dataset and prepared the manuscript of the study.

lan Chi Kei Wong contributed towards the conception of the study design, reviewing the interpretation of data and was involved in approving the final version of the manuscript published. 
Stephen Tomlin contributed towards the conception of the study design, reviewing the interpretation of data and was involved in approving the final version of the manuscript published.

Ellisha Halford contributed towards the conception of the study design, was responsible for part of the acquisition of data across one site, analysis and interpretation of the complete dataset.

Yogini Jani contributed towards analysing, reviewing the interpretation of data and was involved in approving the final version of the manuscript published.

Maisoon Ghaleb contributed towards the conception of the study design, preparing and finalising the manuscript published.

All authors state that they had complete access to the study data to support the publication.

\section{Keywords}

Discharge; interface issues; medication risk; patient safety; medicines reconciliation

Declarations

\section{Conflict of interest}

The Author(s) declare that they have no conflicts of interest to disclose

\section{Funding}

This research received a small grant from University of Hertfordshire small grant

\section{Acknowledgement}

The authors wish to thank Miss CheaXin Lim for her help and assistance with data collection, preparing the data for analysis and quality assurance. 


\section{An evaluation of paediatric medicines reconciliation at hospital discharge into the community}

\section{ABSTRACT}

\section{Objective}

A UK national survey of primary care physicians has indicated that the medication information on hospital discharge summary was incomplete or inaccurate most of the time. Internationally, studies have shown that hospital pharmacist's interventions reduce these discrepancies in the adult population. There have been no published studies on the incidence and severity of the discrepancies of the medication prescribed for children specifically at discharge to date. The objectives of this study were to investigate the incidence, nature and potential clinical severity of medication discrepancies at the point of hospital discharge in a paediatric setting.

\section{Methods}

Five weeks prospective review of hospital discharge letters was carried out. Medication discrepancies between the initial doctor's discharge letter and finalised drug chart were identified, pharmacist changes were recorded and their severity was assessed. The setting of the review was at a London, UK paediatric hospital providing local secondary and specialist tertiary care. The outcome measures were: incidence and the potential clinical severity of medication discrepancies identified by the hospital pharmacist at discharge. 


\section{Key findings}

142 patients (64 female and 78 males, age range 1 month - 18 years) were discharged on 501 medications. The majority of patients were under the care of general surgery and general paediatric teams. One in three discharge letters contained at least one medication discrepancy and required pharmacist interventions to rectify prior to completion. Of these, 1 in 10 had the potential for patient harm if undetected.

\section{Conclusions}

Medicines reconciliation by pharmacist at discharge may be a good intervention in preventing medication discrepancies which have the potential to cause moderate harm in paediatric patients. 


\section{Manuscript}

\section{BACKGROUND AIMS AND OBJECTIVES}

When patients are discharged from hospital, it is important that their medications and any changes that have occurred during their hospital stay are communicated accurately to their next healthcare provider, in order to reduce potentially harmful errors or medication related problems resulting in hospitalisation. ${ }^{[1]}$

A UK government national survey, exploring organisational processes for patients discharged from hospital found that only $27 \%$ of the general practitioners (primary care physicians) reported that the discharge summaries were accurate or complete. Furthermore, $81 \%$ of practices reported that details of the prescribed medications were incomplete or inaccurate on discharge summaries "all" or "most" of the time. ${ }^{[2]}$

Another survey found that doctors themselves updated patient records following hospital discharge in $78 \%$ of their practices, with a small number of surgeries delegating the task to nurses and pharmacists and $17 \%$ to non-clinically trained staff. The report recommended that acute hospital trusts improve the discharge information about medications. The report also recommended guidance for general practices (primary care physician clinics) with regards to reconciling medications after patient discharge. ${ }^{[2]}$

Medication issues across the interface of care between hospital discharge and primary care is not just a UK health systems based problem, as studies identifying drug-related problem have also been explored in other countries such as New Zealand ${ }^{[3]}$ and USA ${ }^{[4]}$. 
Most of the previous research has focused on adult medicines reconciliation and medication errors. ${ }^{[5,6]}$ However, paediatric patients have an increased risk of medication errors specifically dosing errors due to the fact that there is a need for dosage calculations which are individually based on the patient's weight, age, or body surface area and their condition. Also many drugs are unlicensed leading to variances in formulation and potential changes in bioavailability. ${ }^{[7]}$

A review of patient safety incidents in the UK involving medication errors in children found that interface issues may have been a contributing factor. One of the strategies of minimising medication errors in children was improved communication between healthcare professionals in secondary and primary care. However there is little evidence that improved communication would reduce medication errors in children. ${ }^{[8]}$

Furthermore, there is a lack of evidence on medication discrepancies in hospitalised children across the interfaces of care including the point of hospital discharge. ${ }^{[9,10]}$ In one study of medication discrepancies upon discharge in children, it was found that $15 \%$ of children were affected ${ }^{[11]}$

Internationally there is evidence to show that medication discrepancies that occur across the interface of care can be reduced by hospital-based medicines reconciliation practice that involve pharmacist interventions, such as involvement in screening discharge communications and counselling patients at hospital discharge. ${ }^{[12]}$ Randomised controlled trials conducted in the USA ${ }^{[13]}$, Canada ${ }^{[14]}$, and non-RCT studies in the USA ${ }^{[15]}$ and Sweden ${ }^{[16]}$ have demonstrated that pharmacist involvement in the discharge process where they check discharge medication lists have led to a decrease in medication discrepancies at discharge. Previous studies 
and trials observing the benefits of medicines reconciliation at hospital discharge were conducted in adults or were not specific to a paediatric setting. ${ }^{[13,14,15,16]}$

To date, there has been no specific evaluation of the accuracy of the medication prescribed for children specifically at discharge. This information would be essential before developing an intervention and conducting any studies or trials to provide the evidence for the benefit of having a pharmacist led medicines reconciliation service at discharge. It is essential that this stage of discharge is accurate and clear to enable safe and effective transfer of care to the community. Many paediatric medicines reconciliation based studies in the past have mainly aimed to observe medication discrepancies that occur at hospital admission ${ }^{[17,18]}$ with only one small Canadian study published as a conference abstract. This study observed that medication discrepancies occurred at hospital discharge in a very small sample of charts reviewed retrospectively. ${ }^{[11]}$

\section{Aims and Objectives}

The main aims and objectives of this study were to investigate the incidence and nature of medication prescribing discrepancies at the point of hospital discharge in a paediatric setting and assess their potential impact of harm to the patient by evaluating their potential clinical severity. 


\section{METHODS}

A consecutive prospective review of electronically generated discharge medication orders for paediatric patients discharged at a London teaching hospital was conducted over a five week period based on resources available for the study (March to April 2011).

\section{Procedure of discharge medicines reconciliation}

All discharge medication letters that were written by a hospital physician were recorded and transcribed onto a data collection form. This record represented the "initial discharge medication list". Once the discharge letter was amended by a pharmacist after discharge medicines reconciliation (see procedure below), "the pharmacist approved medication list" was recorded in the final discharge letter for the patient to take home and send to the general practice. This information was then recorded onto a data collection form as the "pharmacist's approved discharge medication list". This list was considered the complete and accurate medication list.

A discharge discrepancy was defined as a difference between the "initial discharge medication list" written by the physician when compared against the "pharmacist's approved medication list". The discrepancy was any difference in information between the two lists: - Medication name, brand, dose, dosage form (e.g. modified release, strength of liquid, capsules, tablet), directions and duration. 
The following procedure of medicines reconciliation was adopted by the study hospital and was carried out as routine clinical practice at the time of the study. Up to two days prior to the discharge of the patient an initial medication discharge letter was written by a hospital physician. This medication discharge letter was electronically generated, with the function of free text typing medications that were not on the dropdown list of medications existing on the system. Once this initial discharge medication letter was written, it was passed onto a pharmacist to screen. The pharmacist would check the record based on the final drug chart and would query any discrepancies with the patient's discharging doctor. Once the discrepancies were verified with the doctor and resolved, the pharmacist would return the discharge letter to the discharging doctor to amend on the electronic system and a finalised discharge letter was reprinted and this would be the patient's/caregiver's copy and sent to the community general practice. In addition to the reconciliation, the pharmacist would check the medications dispensed by the hospital pharmacy department and also relabel any patient own medications which required direction of use changes. 


\section{Data collection}

The information that was used during the medicines reconciliation process and recorded for the study were:

1) The finalised drug chart

2) Initial discharge letter written by the doctor using the electronic system

3) The pharmacist's amended version of the discharge letter

4) The finalised and amended discharge letter going out to the patient

5) Discrepancies between the initial discharge letter written by the doctor and the pharmacist's amended version.

\section{Severity assessment of medication discrepancies}

The clinical significance of the discrepancies between the initial prescribed discharge medications and the pharmacist's amendments were assessed using a validated severity rating tool.[19] Five healthcare professionals consisting of 1) a consultant paediatrician (JJ), 2) a consultant pharmacist in paediatrics (ST), 3) a lead pharmacist in medication safety (YJ), 4) a pharmacist/senior lecturer in pharmacy practice $(\mathrm{MG})$, and 5) a research pharmacist $(\mathrm{CH})$ were sent an excel spreadsheet of discrepancies and asked to score the potential severity of each discrepancy using a visual analogue scale. The visual analogue scale was a 10 point scale ranging from 0 which represented no harm to 10 which represented death. The mean score was calculated for each discrepancy and a severity score was assigned using the following criteria: minor harm (scores below 3), moderate harm (scores between 3 and 7) and severe harm (score above 7). ${ }^{[19,20]}$ 


\section{Analysis}

All data from the study, which included the patient's age, condition, specialty, and medication record from the final drug chart to the final discharge letter dispatched to the patient, were recorded. Data were entered into Microsoft Excel and data entry was double checked by $\mathrm{CH}$ and $\mathrm{EH}$ for quality assurance purposes. The cleansed data was then transferred to the software SPSS version 19 for statistical analysis, such as descriptive frequencies in percentages, distributions such as median, interquartile range, and including interrater reliability (Cronbach Alpha) for the severity assessment.

\section{Ethical consideration}

This study was deemed a service evaluation project by the local NHS hospital site Research \& Development Department and therefore NHS ethics committee approval was not required. Although NHS ethics was not required, this project was approved by the School of Pharmacy, University of London Ethics Committee in 2011.

\section{RESULTS}

Over the five week prospective data collection period, 142 patients (64 female and 78 males, age range 1 month - 18 years) were discharged on 501 medications. The patients came from a range of clinical specialties, with the majority of patients under the care of general surgery and general paediatric teams $(n=109,77 \%)$ with few patients under the care of respiratory teams $(n=13,9 \%)$, neurology teams $(n=8,6 \%)$ and other teams $(n=12,8 \%)$. Most of the drugs that were prescribed on the discharge letters were non-opioid analgesic medicines, non-steroidal anti-inflammatory drugs, as well as antibiotics. There were a wide range of other medications. A breakdown of the 
top 20 types of medications ordered on the discharge letter as per British National Formulary is given in Table 1.

On comparing the initial discharge letter and pharmacist amendments, 99/501 (20\%) of medication orders were found to contain discrepancies and $47 / 142(33 \%)$ of patients had at least one discrepancy with a median of 1 discrepancy per patient (range 1 - 12 discrepancies per patient, inter-quartile range $1-3$ ).

The discrepancies were clinically assessed for the potential severity of harm it would pose to the patient, if it had not been identified upon discharge. The interrater reliability of the scorings between the 5 judges was calculated to be a Cronbach alpha value of 0.872 , which reflected a high level of reliability. Of the 99 discrepancies, $78 \%$ (77/99) had scores of $<3$ representing potential of minor harm, and $22 \%(22 / 99)$ of discrepancies (affecting 15 patients) had scores of 3-7 representing potential for moderate harm; none of the discrepancies were considered to have severe harm potential. The median severity score was 1.48 (IQR $=0.71-2.89$, minimum 0.18 , maximum 6.38). Examples of potentially minor and moderately severe discrepancies are shown on Table 2. Medication discrepancy types with examples are presented in Table 3.

\section{DISCUSSION}

The results from this first UK prospective study of the accuracy of discharge letters in paediatric patients showed that a third of the discharge letters written by the hospital physicians contained discrepancies when compared to the pharmacist's checked and amended final version. The discrepancies were identified and rectified by hospital pharmacists who screened the discharge letters for accuracy and reconciled the medication list as part of their routine clinical work. 
Our study adds to and strengthens the evidence base of medicines reconciliation at discharge for children. The only similar study identified from existing literature, was a retrospective review of discharge letters at a paediatric hospital in Canada which indicated that 12 out of $28(42 \%)$ of patients had at least one discharge discrepancy between the discharge medication ordered and a "best practice medication discharge plan". This Canadian study had a higher proportion of discrepancies than our study, despite having a small sample size which means that the result could possibly be due to random fluctuation. ${ }^{[11]}$ In comparison to adult studies, our discrepancy incidence of $33 \%$ differed to the incidence found in USA and Canadian studies, which found a higher rate of $59.6 \%$ and $41.3 \%$ respectively. ${ }^{[21,15]}$ These figures may not be comparable as different definitions had been used to define a discrepancy in each study. There were a number of limitations to the study. The study was conducted in one paediatric hospital in the UK and the duration of the study was short. Only the discharge letters that were reviewed within pharmacy operational hours were included in the study. Pharmacist amendments of the discharge letter were recorded on a data collection form, however the individual discussions between the doctor and pharmacist making the change were not recorded. Furthermore, some medication discrepancies might not have been identified via the pharmacist's check. Despite these limitations, the study suggests that there are problems and issues of a moderately severe nature when discharge prescriptions are written to transfer children from one setting to another.

The current study showed that in terms of potential patient safety risk in the absence of a pharmacist's check, $22 \%$ of unintended discrepancies at discharge had 
the potential to cause moderate harm if not resolved. These discrepancies were identified by a paediatric ward pharmacist as differing from the discharging drug chart and were verified as unintended - e.g. it was not intentional by the physician. This finding strikes similarities when compared to other studies. In a Canadian adult study by Wong et al. there were $29.5 \%$ of unintended discrepancies at discharge that had the potential to cause possible or probable patient discomfort or clinical deterioration. ${ }^{[21]}$ However, the clinical severity assessment methodology in both studies was different in our study, we used a visual analogue scale with five assessors, and the study by Wong et al used a three point scale rating by three assessors. The study outcomes of the current study had a lower incidence of patients who had discrepancies when compared with an Irish study of cardiology adult patients by Grimes et al, which found a higher incidence of $65 \%$ of patients with at least one unintended discrepancy. ${ }^{[22]}$ However the discrepancies from this adult study of cardiology patients also did not have potentially serious discrepancies when assessed for severity of clinical outcome and only had $47 \%$ of discrepancies being minor and $53 \%$ being moderate. The study by Grimes et al. used the same method of severity assessment. One US adult study that explored discharge discrepancies reported higher incidences of discrepancies when compared to the current study, with the incidence reported at $45 \%$, however the study cohort were limited to patients being prescribed dysphagia medications on discharge letters. ${ }^{[23]}$

Our study suggests that pharmacists screening and review of discharge medication letters prevents 1 in 5 potentially harmful discrepancies from leaving the hospital. This study highlights and provides evidence for pharmacists to conduct 
medicines reconciliation at discharge in children. Reconciliation at discharge is shown to improve the accuracy of discharge letter by directly reducing medication errors. This finding provides supporting evidence and justifies the role and routine clinical practice of pharmacists carrying out medicines reconciliation at discharge to keep patients safe.

Further work is required to assess the generalisability of the findings, by repeating the study and measure the impact of pharmacist led discharge medicines reconciliation in children at other sites, and to explore the causes of the discrepancies identified. An intervention can then be modelled and developed once the causes of discrepancies are better understood. As medicines reconciliation has been adopted across paediatric hospitals and other hospitals across England that have paediatric wards, conducting a Randomised Controlled Trial would not be feasible ${ }^{[24]}$. As the economic evidence of pharmacist led medicines reconciliation at hospital admission was found to be a cost effective intervention to prevent medication errors, ${ }^{[25]}$ a future study of the cost effectiveness of medicines reconciliation at discharge is required. There is also a need to evaluate the accuracy of discharge letters written out of hours where pharmacist cover is reduced.

\section{CONCLUSION}

This study highlights that one in three discharge letters written by discharging physicians contained at least one medication discrepancy, all of which were resolved by the pharmacist. This finding supports the role of pharmacist led medicines reconciliation as an intervention to prevent these discrepancies from occurring. 
Further work is required to find out if medication discrepancies occur post hospital discharge. 


\section{REFERENCES}

1. WHO Collaborating Centre for Patient Safety Solutions. Assuring Medication Accuracy at Transitions in Care. Patient Safety Solutions 2007, volume 1, solution 6 | May 2007. Accessed online (17 ${ }^{\text {th }}$ April 2013) at: -

http://www.who.int/patientsafety/solutions/patientsafety/PS-Solution6.pdf

2. Care quality commission. National study. Managing patients' medicines after discharge from hospital. October 2009. Accessed online (17 th April 2013) at:

http://archive.cqc.org.uk/ db/ documents/Managing patients medicines afte r discharge from hospital.pdf

3. Maxwell K, Harrison J, Scahill S, Braund R. Identifying drug-related problems during transition between secondary and primary care in New Zealand. 2013;21:333-336.

4. Coleman EA, Smith JD, Raha D, Min S-J. Posthospital Medication Discrepancies. Prevalence and Contributing factors. Arch Intern Med 2005;165:1842-1847.

5. Campbell, F., Karnon, J., Czoski-Murray, C., Jones, R. 2007. A systematic review of the effectiveness and cost-effectiveness of interventions aimed at preventing medication error (medicines reconciliation) at hospital admission. Accessed online $\left(12^{\text {th }}\right.$ March 2015$)$ at:

https://www.nice.org.uk/guidance/psg001/documents/systematic-review-forclinical-and-cost-effectiveness-of-interventions-in-medicines-reconciliation-atthe-point-of-admission2

6. Tam, V.C., Knowles, S.R., Cornish, P.L., et al. Frequency, type and clinical importance of medication history errors at admission: a systematic review. Canadian Medical Association Journal, 2005,173(5), pp. 510-5.

7. Ghaleb M, Wong ICK. Medication Errors in Paediatric Patients. Arch Dis Child: Education and Practice edition. 2006:91:ep20-ep24

8. Wong ICK, Wong L, Cranswick N. Minimising medication errors in children. Arch Dis Child. 2009;94:161-164

9. Wong ICK, Basra N, Yeung V, Cope J. Supply problems of unlicensed and off-label medicines after discharge. Arch Dis Child 2009:91:686-688 
10. Huynh C, Wong, IC, Tomlin S, et al. Medication discrepancies at transitions in pediatrics: A review of the literature. Pediatric Drugs 2013;15(3):203-215.

11. Ling J, Caligiuri C, Galloway L, et al. Medication reconciliation: Towards a "Best Practice Medication Discharge Plan" in a Pediatric Hospital. Can J Hosp Pharm. 2009;62:345

12. Mueller SK, Sponsler KC, Kripalani S, et al. Health Care Reform. HospitalBased Medication Reconciliation Practices. A systematic review. Arch Intern Med. 2012;172:1057-1069

13. Schnipper JL, Kirwin JL, Cotugno MC, et al. Role of Pharmacist Counseling in Preventing Adverse Drug Events After Hospitalization. Arch Intern Med. 2006;166:565-571

14. Nickerson A, MacKinnon, NK, Roberts N, Saulnier L. Drug-Therapy Problems, Inconsistencies and Omissions Identified During a Medication Reconciliation Seamless Care Service. Healthcare quarterly 2005:8:65-71

15. Walker PC, Bernstein SJ, Tucker Jones JN, et al. Impact of a PharmacistFacilitated Hospital Discharge Program. Arch Intern Med 2009:169:2003-2010

16. Bergkvist A. Midlov P, Hoglund P, Larsson L, Bondesson A, Eriksson T. Improved quality in the hospital discharge summary reduces medication errors - LIMM: Landskrona Integrated Medicines Management. Eur J Clin Pharmacol 2009:65:1037-1046

17. Coffey M, Mack L, Streitenberger K, et al. Prevalence and clinical significance of medication discrepancies at pediatric hospital admission. Academic Pediatrics 2009;9:360-366

18. Terry DR, Solanki GA, Sinclair AG, et al. Clinical Significance of Medication reconciliation in Children Admitted to a UK pediatric hospital. Paediatr Drugs, 2010;12:331-337.

19. Dean BS, Barber N. A validated reliable method of scoring the severity of medication errors. American Journal of Health-System Pharmacists. 1999;56:57-62.

20. Dean BS. A transatlantic study of medication system errors in hospitals. London: University of London, 1993. 
21. Wong JD, Bajcar JM, Wong GG, et al. Medication reconciliation at hospital discharge: Evaluating discrepancies. Annals of Pharmacotherapy. 2008;42(10):1373-1379.

22. Grimes T, Delaney T, Duggan C, et al. Survey of medication documentation at hospital discharge for patient safety and continuity of care. Irish Journal of Medical Science. 2008;177:93-97

23. Kind $\mathrm{A}$, Anderson $\mathrm{P}$, Hind $\mathrm{J}$, et al. Omission of dysphagia therapies in hospital discharge communications. Dysphagia. 2011;26:49-61

24. Huynh, C., Jani, Y., Wong, I. C. K., Dewchand, B. and Tomlin, S. What is the current practice of medicines reconciliation in children nationally in the UK? International Journal of Pharmacy Practice 2013:21(1):62-65

25. Karnon J, Campbell F, Czoski-Murray C. Model-based cost-effectiveness analysis of interventions aimed at preventing medication error at hospital admission (medicines reconciliation). Journal of Evaluation in Clinical Practice. 2009;15(2):299-306. 
Table 1 List of the top 20 medications ordered on the discharge letter per British

National Formulary classification

\begin{tabular}{|l|r|}
\hline BNF Chapter - Drug categories & $\begin{array}{r}\text { Number of Drugs } \\
\text { (Frequency) }\end{array}$ \\
\hline 4.7.1 Non-opioid analgesic & 95 \\
\hline 10.1.1 Non-steroidal anti-inflammatory drugs & 67 \\
\hline 5.1.1 Penicillins & 51 \\
\hline 4.8.1 Control of the epilepsies & 21 \\
\hline 1.6.4 Osmotic laxatives & 20 \\
\hline 4.7.2 Opioid analgesic & 17 \\
\hline 1.3.1 H2-receptor antagonists & 14 \\
\hline 3.1.1.1 Selective beta2 agonists & 10 \\
\hline 3.2 Corticosteroids & 10 \\
\hline 9.1.1.1 Oral iron & 10 \\
\hline 1.6.2 Stimulant laxatives & 9 \\
\hline 1.3.5 Proton pump inhibitors & 8 \\
\hline 1.5.2 Corticosteroids & 8 \\
\hline 4.6 Drugs used in nausea and vertigo & 8 \\
\hline 6.1.1 Insulins & 7 \\
\hline 3.4.1 Antihistamines & 6 \\
\hline 4.1.1 Hypnotics & 6 \\
\hline 10.2.2 Skeletal muscle relaxants & 5 \\
\hline 13.2.1.1 Emollient bath and shower preparations & 5 \\
\hline 4.8.2 Drugs used in status epilepticus & 5 \\
\hline
\end{tabular}

Table 2: Example of a minor and moderate discrepancy

\begin{tabular}{|l|l|l|l|l|l|}
\hline $\begin{array}{l}\text { Patient } \\
\text { ID }\end{array}$ & $\begin{array}{l}\text { Age } \\
\text { (year, } \\
\text { months) }\end{array}$ & $\begin{array}{l}\text { Weight } \\
\mathbf{( k g )}\end{array}$ & Description of discrepancy & $\begin{array}{l}\text { Mean } \\
\text { score }\end{array}$ & Severity \\
\hline 22 & 14 years & 28.8 & $\begin{array}{l}\text { Initial TTA does not state that } \\
\text { ranitidine 90mg twice a day should } \\
\text { only be used "whilst on ibuprofen } \\
\text { only" }\end{array}$ & 1.71 & Minor \\
\hline 138 & $\begin{array}{l}3 \text { years 5 } \\
\text { months }\end{array}$ & 13.2 & $\begin{array}{l}\text { In the initial TTA the patient was } \\
\text { prescribed Sodium Valproate 200mg } \\
\text { suspension to be taken twice daily. } \\
\text { This was changed to three times daily } \\
\text { which was the patient's current dose } \\
\text { in the final TTA. }\end{array}$ & 4.36 & Moderate \\
\hline
\end{tabular}


Table 3 - Types of discharge discrepancies

\begin{tabular}{|c|c|c|}
\hline $\begin{array}{l}\text { Type of discrepancy at } \\
\text { discharge }\end{array}$ & Example of discrepancy & $\begin{array}{l}\text { Frequency } \\
\text { (percentage out of } \\
142 \text { discrepancies } \\
\text { in total) }\end{array}$ \\
\hline $\begin{array}{l}\text { Directions of use, including } \\
\text { formulation, route and } \\
\text { duration. }\end{array}$ & $\begin{array}{l}\text { Direction example } \\
11 \text { year old patient. } 39.8 \mathrm{~kg} \text {. } \\
\text { The initial discharge letter for TTA stated that } \\
\text { Dermol was initially directed to be used every } \\
\text { morning, but changed to be used as a soap } \\
\text { substitute on the final TTA. } \\
\text { Direction and route } \\
7 \text { years } 7 \text { months old patient. } 14.4 \mathrm{~kg} \\
\text { Baclofen } 5 \mathrm{mg} \text { liquid three times daily via oral } \\
\text { route on initial TTA, changed to liquid - take } 5 \mathrm{mg} \\
\text { twice daily via PEG on final TTA. } \\
\text { Formulation } \\
6 \text { years } 7 \text { months. } 23 \mathrm{~kg} \text {. } \\
\text { On initial TTA Paracetamol tablets were } \\
\text { prescribed, switch to liquid on final TTA. Dose } \\
\text { was } 250 \mathrm{mg} \text { four times a day. } \\
\text { Duration } \\
11 \text { months } 2 \text { weeks old patient. } 11 \mathrm{~kg} \text {. } \\
\text { On the initial TTA Flucloxacillin } 62.5 \mathrm{mg} \text { four } \\
\text { times a day is to be taken for six days and } \\
\text { stopped on } 15 / 3 / 11 \text {, stop date changed by the } \\
\text { pharmacist to } 21 / 3 / 11\end{array}$ & $34(24 \%)$ \\
\hline Incorrect form & $\begin{array}{l}12 \text { year old patient. } 29.7 \mathrm{~kg} \text {. } \\
\text { On initial TTA Insulin Levemir } 6 \text { units } \\
\text { subcutaneous injection each night was } \\
\text { prescribed as Flexpen, changed to cartridge by } \\
\text { pharmacist on final TTA. }\end{array}$ & $28(20 \%)$ \\
\hline Omitted medication & $\begin{array}{l}16 \text { year old patient. } 73.8 \mathrm{~kg} \text {. } \\
\text { Biscacodyl } 4 \mathrm{mg} \text { rectal solution - take every other } \\
\text { day - was omitted from initial discharge letter for } \\
\text { the TTA, added on by pharmacist. }\end{array}$ & $15(11 \%)$ \\
\hline No longer required drugs & $\begin{array}{l}2 \text { years } 1 \text { month. } 9.76 \mathrm{~kg} \text {. } \\
\text { Topiramate } 30 \mathrm{mg} \text { tablets - } 30 \mathrm{mg} \text { twice a day } \\
\text { taken off TTA by pharmacist, deemed } \\
\text { unnecessary. }\end{array}$ & $14(10 \%)$ \\
\hline Duplicated medication & $\begin{array}{l}\text { Patient } 5 \text { years } 9 \text { months. } 20 \mathrm{~kg} \text {. } \\
\text { Gabapentin } 100 \mathrm{mg} \text { to be taken three times daily } \\
\text { duplicated on discharge letter for TTA. }\end{array}$ & $9(6 \%)$ \\
\hline Incorrect dose & $\begin{array}{l}\text { Patient } 11 \text { years. } 39.8 \mathrm{~kg} \text {. } \\
\text { Clonazepam } 250 \mathrm{mg} \text { suspension - take } 250 \mathrm{mg} \\
\text { each morning on initial TTA changed to } 200 \mathrm{mg} \\
\text { suspension - take } 200 \mathrm{mg} \text { each morning }\end{array}$ & $8(6 \%)$ \\
\hline $\begin{array}{l}\text { Incorrect medicine (including } \\
\text { spelling errors) }\end{array}$ & $\begin{array}{l}4 \text { months } 1 \text { week. } 2.8 \mathrm{~kg} \text {. } \\
\text { Incorrect spelling of medicine- Syntron } 1 \mathrm{ml} \text { oral } \\
\text { each morning written on TTA instead of Sytron }\end{array}$ & $3(2 \%)$ \\
\hline
\end{tabular}

